\title{
複数台ロボットによる協調作業経路計画
}

\author{
山本 元 司* 黒 田 創 明** 毛利 彰*
}

\section{A Path Planning for Coordinated Work by Multi-Robot System}

\author{
Motoji YAMAMOTO Soumei KURODA Akira MOHRI
}

\begin{abstract}
This paper discusses a path planning problem for a coordinated work by multi-robot system. The problem is how to move each robot's arm cooperatively to execute specified works. Various styles of coordinated work, which is based on the classification from a kinematic point of view for the relation of each robot's end-effector, are discussed. Mainly in this paper, a work while one robot is holding or carrying a workpiece, another robot executes a specified work with tools, is developed as a typical example of an interest coordinated work. The redundancy peculiar to the coordinated work is presented by the kinematic analysis of two-robot system. An algorithm to plan a coordinated motion is proposed by using the redundancy. As numerical examples, the proposed method is applied to a coordinated motion planning by two planar manipulators with three-links.
\end{abstract}

Key Words : Coordinated work, Motion planning, Redundant degrees of freedom, Multi-robot system

\section{1. ま えがき}

従来主に単体のロボットにより行ってきた作業に対し， 複数台ロボットを協調的に動作させてその作業を遂行す ることが考えられている.これはこのよらな協調作業は 単体のロボットによる作業にないいくつかの特長を持つ と考えられているからである. 例えば細長い重量物のワ ークの移動は，機構的にオープンループの形態をとるこ との多い単体のロボットでは苦手な作業であるが，2台 のロボットを用いると, 一台あたりのワークの重量によ る負荷が半減されるばかりでなく，クローズドループの 機構となることで，モーメントによる負荷が大幅に軽減 される、をた，複数台のロボットによる作業により実質 的な作業域が拡大し，より良い作業姿勢を確保し易いこ とや, 単体のロボットでは実現困難な複雑で高精度な作 業軌跡を描くことができること等が考えられる. しかし このような複数台ロボットシステムを用いた協調作業は, 単体のロボットによる作業に比べ，協調的な動作制御が 複雑になり，実際にはいくつかの例1),2) を除きそれほど

\footnotetext{
原稿受付 1992 年 2 月 13 日

* 九州大学工学部 ** 九州大学大学院
}

実現されていないのが現状である.

初期の複数台ロボットによる協調動作の研究は, この 問題が多指ハンドの動作制御の問題ときわめて類似して いることから，多指ハンドに関する多くの研研で議論さ れた把持力の最適化問題や，協調的操り問題などについ て, これを複数台ロボットの協調動作問題として扱って (る多くの研究3),4),5) がある. また, 多指ハンドの研究 ではそれ匡ど問題とされていなかった，ダイナミクスの 問題が複数台ロボットによる動作制御においては意味を 持つため, 作業対象物のダイナミクスを考慮したらえで の制御法 ${ }^{6}$ や両手協調動作のためのハイブリッド制御系 を構成する力法てなどが検討されている. また一つの物 体を 2 台のロボットで移動する場合の移動時間を最短に する関節トルクを計算する問題も検討されている ${ }^{8), 99,10)}$.

一方, 協調ロボットシステムの多くは運動学的に圥長 な自由度を持つことから単体の冗長ロボットでの研究に おいて議論されてきた手法を複数台の協調ロボットシス テムに適用しようとする研究がなされている.このよう な研究として, Dauchez ら ${ }^{11)} 2$ 台協調ロボットの運 動学式の冗長性の利用を検討し，Kumar ら ${ }^{12)}$ は複数台 ロボットシステムの運動学的性能指標を検討している。 
また Lee ら ${ }^{13)}$ は複数台ロボットシステムにおいて, 各 ロボットの可操作楕円体を計算し，これらの交差領域の 体積でシステムの運動学的性能を評価している ${ }^{18)}$. さら に, Chiacchio ら ${ }^{14)}$ は複数台ロボットシステムの一般的 な運動学の定式化から, 複数台ロボットシステムに払張 した可操作楕円体を定義している.

ところで複数台ロボットシステムを用いて実際に与え られた作業を行らためには，各ロボットがどのような作 業姿勢で，どのように関節を協調動作させるかを考えな ければならない.これは協調作業経路計画問題と呼ぶこ とができるが, 協調ロボットシステムにおける運動学的 な自由度と拘束条件をどう扱うかが問題であり，この問 題を検討している研究は現在のところ比較的少ない. 関 連する研究としては, Jouaneh らによるポジショニング テーブルと多関節型ロボットによる協調動作を用いて,

作業座標でロボット手先を鋭いコーナーを減速せず通 過させるための協調的な関節軌道生成問題を扱った研 究 15),16)や, Carriker らによるベースが移動可能な協調 ロボット.システムにより，与えられた作業経路を実現す る協調作業経路のなかで定義したコストを最小にする経 路を計画する問題を検討したもの吾)がある. しかし，こ れらは複数台口ボットの協調による一般的な作業形態を 検討しているわけではなく，特殊な作業に限定しての経 路計画問題を扱っている.

そこで本研究では与えられた作業を実現するための協 調的な作業形態の検討と, この検討から示される興味あ る複雑な協調作業形態の典型的な実現例して，2台の口 ボットすなわち、ワークを保持したロボットと，作業の ための工具を装着したロボットによる協調動作を検討し， 与えられた作業を実現するための協調作業経路計画問題 に対する具体的な経路生成法を提案する. 以下， 2 章で 複数台ロボットによる協調作業形態の検討をおこない, 3 章では複雑な協調作業の一例として，2台のロボット そよる同時協調的な作業の運動学解析をおこなう.さら に 4 章ではこの問題に対する協調作業経路計画法の提案 をして，具体的なアルゴリズムを示す． 5 章では 2 台の 平面 3 リンクロボットによるいくつかの協調作業関節経 路の例題を示し, 経路計画法の有効性を確認する.

\section{2. 複数台ロボットによる協調形態}

現在までの協調動作の研究の多くは一つの対象物を操 作，移動させる作業を取り扱っている. しかし，より複 雑な作業形態を考えることもできる. 例えば Fig. 1 に 見られるナイフを用いたリンゴの皮剝き作業を考えてみ よう.これは右手（腕）と左手（腕）による協調作業の 一例である. 右手でナイフを持ち, 皮を豩く動作をおこ

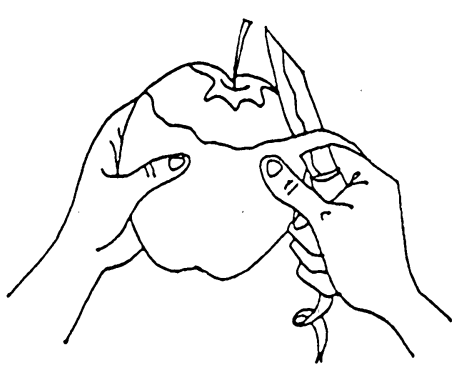

Fig. 1 A coordinated work to pare an apple

なっているが, 同時に左手も単にリンゴを固定している たけでなく，皮剶きの動作にも貢献している. このこと は固定されたリンゴをナイフを持った右手のみで皮を剝 くことはたいへん難しいし，固定されたナイフを用いて リンゴを持った左手のみで皮を剝くことも困難であるこ とから理解できる.

そこでこのような協調動作による作業形態をより一般 的に考え, 複数台ロボットによる一般的な協調作業形態 を検討する. ロボットによる協調作業，あるいは協調動 作といら言葉は, 多くの研究の中で様々な意味に用いら れており，必ずしも明確な定義づけがなされているわけ ではない，従って混乱を防ぐために，本研究で考える協 調動作の定義をしておくべきであろう．その定義として， ここでは複数台のロボットがある作業を行っているとし て，“任意に選ばれた 2 台の口ボットが与えられた作業 を実現するために協調動作をおこなっている”とは,

1. 2 台のロボットは同時に一つの作業を行っている.

2. もしどちらか一方でも動作を停止したなら, 与え られた作業の遂行は不可能になるかまたは困難にな る.

の 2 つ条件を満たす場合を言らことにする.ここで若 干の補足をしておく．ここでの定義は複数台のロボット システムのなかで特定の 2 台のみに注目し，その 2 台の 関係に打いての協調を考えている. 従ってょり上のクラ スすなわち，多くのロボット相互の関係を考える場合に おける協調の問題はここでは取り扱わない.また，これ はロボットによる作業を実現するらえでの協調を定義し たものであり，別の観点からの協調の定義ももちろんあ りらる.ささて，このように定義された協調動作により協 調作業をおこなら 2 台のロボットの両手先の位置と姿勢 に着目して，運動学的な視点から見れば Table 1 のよ らに協調作業を分類することが可能である注 1).

注 1 ）この分類は内山らが述べている密結合, 疎結合, 非結 合7) といら分類に類似しているが，ここで作業の実現 といら観点からの分類であること，より具体的な定義づ けを行っている点で異なり, 分類の意味づけも多少異な る. 
Table 1 Classification of coordinated work

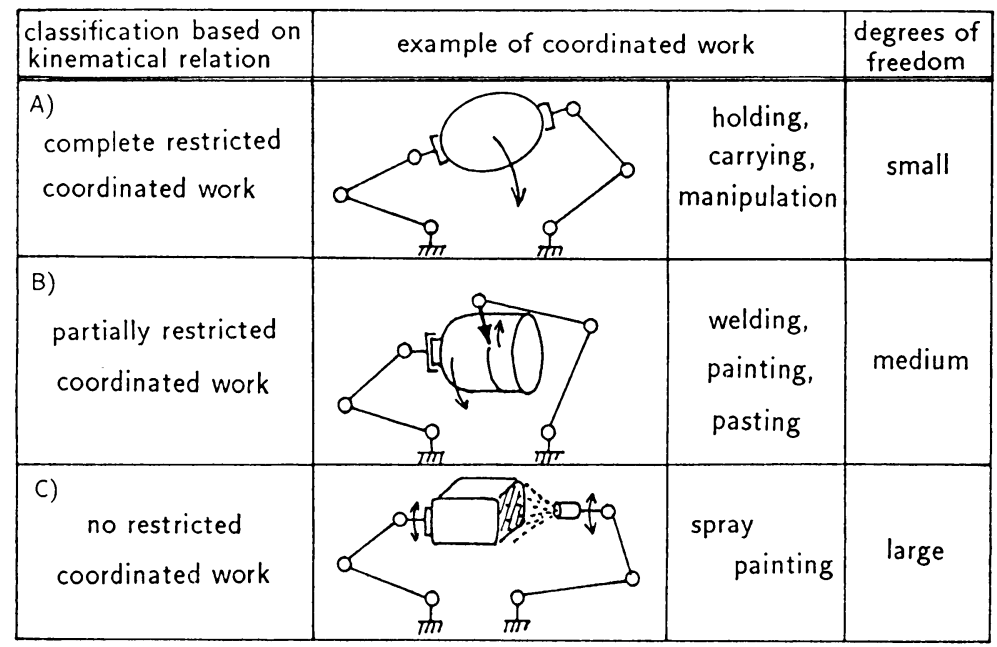

\section{A）完全拘束協調作業：}

作業中に両ロボットの手先位置 (姿勢) の相対変化は しない. 具体的な作業としては Table 1 に見られるよう に, 一つの物体をしっかりつかんで移動, 操作する場合 が考えられる.

\section{B）部分拘束協調作業：}

手先位置 (姿勢) の相対的変位はあるが, ある幾何学 的関係により部分的に拘束される. 作業としては溶接, 糊付け，絵つけなどが考えられる.

\section{C）非拘束協調作業 :}

手先位置 (姿勢) の相対的関係は衝突の問題を除けば 基本的に自由である．例として，Table 1 に見られるよ うな塗装作業が考えられる.

A）の作業形態は複数台ロボットシステムの協調動作 に関する研究でよく取り上げられてきたものであり、シ ステム全体としての運動学的な自由度は小さい。また C）の作業形態における経路計画として問題となるのは, 主として複数台ロボットによる衝突回避問題であろら. この問題についての研究もいくつかなされている. 興味 深いのはB）の場合の作業形態である．従来このような 作業形態はあまり検討されていなかった，B）に分類さ れる作業は理論的にはいくらでも考えられるが，現実的， 典型的な例として，一方のロボット (robot-A) でワー クをしっかりと把持し，もう一方のロボット（robot-B） は手先に工具を装着し，これを用いて作業を行う場合を 考える.このよらな作業形態は次のような点でたいへん 興味深い.

1. robot-A は単にワークを把持するだけでなく, 作 業の遂行に都合の良いように姿勢を変更することで
作業の遂行自体に貢献することが可能である.この 点はリンゴの皮䟝き作業と共通する.

2. 作業を遂行することのみを目的とするなら，把持 物体の位置と姿勢は一般に任意となる.この自由度 を1で述べたように用いることもできるが、ワーク を移動させながら，同時にそのワークに対し加工な どの作業を行らことで生産性を向上させることも考 えられる.

そこで以下本論文ではこのような作業形態に関する協 調動作経路計画問題を取り扱らことにする.

\section{3. 協調動作の定式化}

\section{1 記 奇}

ここでは 2 章で議論したB）の作業形態を検討する. 協調動作の定義でも述べたように，2台のロボットに着 目して一般の複数台のロボットによる協調作業を検討す るため,ここでの定式化においては 2 台のロボットによ る両手先の相対変位が部分的に制限される場合の協調作 業を考え, この場合の運動学的関係を導く.

robot-A は手先につけられたグリッパで物体をしっか りと固定しており, robot-B の手先には作業を遂行する ための工具が装着されているものとする. また 2 台の口 ボットはそれぞれ手先の任意の位置と姿勢が取り得るた めに必要十分な 6 自由度を持つものとし，基準座標系か らみた各ロボットのベースの位置と姿勢は变化しないも のとする.この 2 台のロボットで与えられた作業を協調 的におこなう．作業は作業変数（物体座標系でみた作業

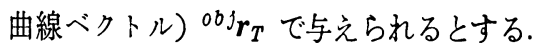

以下に本論文で用いる記号を以下のように定める 


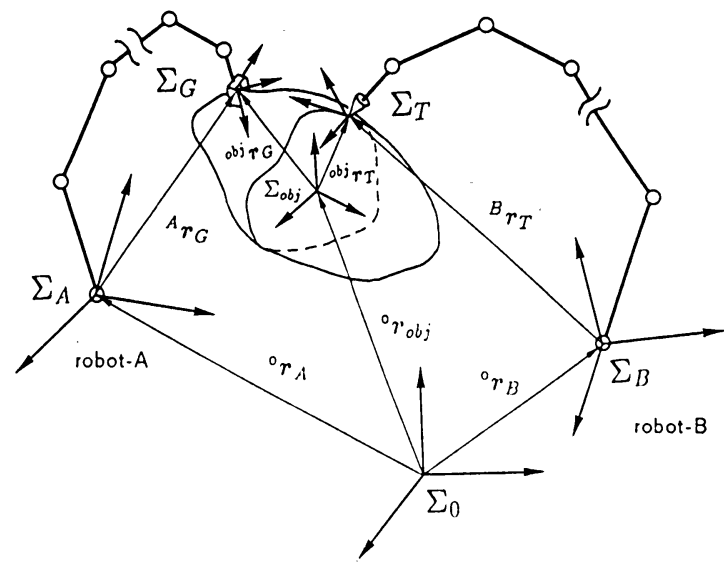

Fig. 2 Coordinate systems

(Fig. 2 参照).

$\boldsymbol{\theta} \in \Re^{6}:$ robot-A の関節変数

$\boldsymbol{q} \in \mathfrak{R}^{6}:$ robot-B の関節変数

${ }^{0} \boldsymbol{r}_{A},{ }^{0} \boldsymbol{r}_{B}$ : 基準座標系 $\left(\Sigma_{0}\right)$ でみた robot-A, robot-B のベース座標系 $\left(\sum_{A}, \Sigma_{B}\right)$ の原点の位置ベクトル

${ }^{A} \boldsymbol{r}_{G}(\boldsymbol{\theta}),{ }^{B} \boldsymbol{r}_{T}(\boldsymbol{q}): \sum_{A}, \sum_{B}$ でみたグリッパ座標系, $\left(\Sigma_{G}\right)$, ッール座標系 $\left(\Sigma_{T}\right)$ の原点 の位置ベクトル

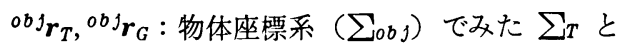
$\sum_{G}$ の原点の位直ベクトル

${ }^{0} \dot{r}_{o b j}: \Sigma_{0}$ でみた $\sum_{o b j}$ の原点の位置べク トル

${ }^{0} \boldsymbol{R}_{A},{ }^{0} \boldsymbol{R}_{B}: \Sigma_{A}, \Sigma_{B}$ から $\Sigma_{0}$ への回転行列 ${ }^{A} \boldsymbol{R}_{G}(\boldsymbol{\theta}),{ }^{B} \boldsymbol{R}_{T}(\boldsymbol{q}): \Sigma_{G}, \Sigma_{T}$ から $\Sigma_{A}, \Sigma_{B}$ への回転行 列

${ }^{o b j} \boldsymbol{R}_{G},{ }^{o b j} \boldsymbol{R}_{T}: \Sigma_{G}, \Sigma_{T}$ から $\sum_{o b j}$ 人の回転行列

${ }^{0} \boldsymbol{R}_{o b j}: \sum_{0 b j}$ から $\sum_{0}$ への回転行列

${ }^{0} \boldsymbol{\omega}_{A},{ }^{0} \boldsymbol{\omega}_{B}: \Sigma_{0}$ でみた $\Sigma_{A}, \Sigma_{B}$ の角速度べ トル

${ }^{A} \boldsymbol{\omega}_{G},{ }^{B} \boldsymbol{\omega}_{T}: \Sigma_{A}, \Sigma_{B}$ でみた $\Sigma_{G}, \Sigma_{T}$ の角速度 ベクトル

${ }^{o b j} \boldsymbol{\omega}_{T}: \sum_{o b j}$ でみた $\sum_{T}$ の角速度ベクトル

${ }^{0} \omega_{o b j}: \Sigma_{0}$ でみた $\sum_{o b j}$ の角速度ベクトル

\section{2 物体の位置, 姿勢が任意の場合の運動学}

ここでは作業対象物の位置と姿勢は特に与えられてお らず，作業を遂行するための作業变数 ${ }^{\circ b j} \dot{\boldsymbol{r}}_{T},{ }^{0 b j} \boldsymbol{\omega}_{T}$ の み与えられている場合の協調作業の運動学を検討寸る.

Fig. 2 から明らかなよらに $\Sigma_{0}$ でみた $\Sigma_{T}$ の原点の 位置ベクトル ${ }^{0} \boldsymbol{r}_{T}$ は

$$
{ }^{0} \boldsymbol{r}_{T}={ }^{0} \boldsymbol{r}_{A}+{ }^{0} \boldsymbol{R}_{A}{ }^{A} \boldsymbol{r}_{G}(\boldsymbol{\theta})+{ }^{0} \boldsymbol{R}_{A}{ }^{A} \boldsymbol{R}_{G}(\boldsymbol{\theta})^{G} \boldsymbol{r}_{o b} \mathrm{~J}
$$

$$
\begin{aligned}
& +{ }^{0} \boldsymbol{R}_{A}{ }^{A} \boldsymbol{R}_{G}(\boldsymbol{\theta})^{G} \boldsymbol{R}_{o b j^{o b j} \boldsymbol{r}_{T}} \\
= & { }^{0} \boldsymbol{r}_{B}+{ }^{0} \boldsymbol{R}_{B}{ }^{B} \boldsymbol{r}_{T}(\boldsymbol{q})
\end{aligned}
$$

‘とかける. ただし ${ }^{G} \boldsymbol{r}_{o b j}$ は $\Sigma_{G}$ でみた $\sum_{o b j}$ の原点の 位置ベクトル. ${ }^{G} \boldsymbol{R}_{o b j}$ は $\sum_{o b j}$ から $\sum_{G}$ への回転行列 である. 回転行列の性質から

$$
{ }^{G} \boldsymbol{r}_{o b j}=-{ }^{G} \boldsymbol{R}_{o b j}{ }^{o b j} \boldsymbol{r}_{G}=-{ }^{o b j} \boldsymbol{R}_{G}{ }^{T o b j} \boldsymbol{r}_{G}
$$

と表わすことができ，これを用いると ${ }^{\circ b{ } \boldsymbol{r}_{T}}$ は

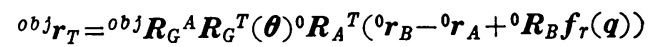

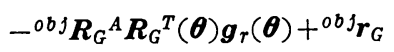

となる.ただし，

$$
\begin{aligned}
& \boldsymbol{g}_{r}(\boldsymbol{\theta})={ }^{A} \boldsymbol{r}_{G}(\boldsymbol{\theta}) \\
& \boldsymbol{f}_{r}(\boldsymbol{q})={ }^{B} \boldsymbol{r}_{T}(\boldsymbol{q})
\end{aligned}
$$

ここで各ロボットのベース座標系でみた手先位置, 姿勢 と各関節角との微分関係を表すャコビ行列を

$$
\begin{array}{ll}
{ }^{A} \dot{\boldsymbol{r}}_{G}(\boldsymbol{\theta})=\boldsymbol{J}_{g r}(\boldsymbol{\theta}) \dot{\boldsymbol{\theta}} & { }^{A} \boldsymbol{\omega}_{G}=\boldsymbol{J}_{g \phi}(\boldsymbol{\theta}) \dot{\boldsymbol{\theta}} \\
{ }^{{ }^{B} \dot{\boldsymbol{r}}_{T}(\boldsymbol{q})}=\boldsymbol{J}_{f r}(\boldsymbol{q}) \dot{\boldsymbol{q}} & { }^{B} \boldsymbol{\omega}_{T}=\boldsymbol{J}_{f \phi}(\boldsymbol{q}) \dot{\boldsymbol{q}}
\end{array}
$$

として, (3) 式の両辺を微分すると,

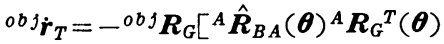

$$
\begin{aligned}
& +{ }^{A} \hat{\boldsymbol{R}}_{T}(\boldsymbol{\theta}, \boldsymbol{q})^{A} \boldsymbol{R}_{G}{ }^{T}(\boldsymbol{\theta}) \\
& \left.-{ }^{A} \hat{\boldsymbol{R}}_{G}(\boldsymbol{\theta})^{A} \boldsymbol{R}_{G}{ }^{T}(\boldsymbol{\theta})\right] \boldsymbol{J}_{g \phi}(\boldsymbol{\theta}) \dot{\boldsymbol{\theta}} \\
& { }^{\circ o b j} \boldsymbol{R}_{G}{ }^{A} \boldsymbol{R}_{G}{ }^{T}(\boldsymbol{\theta}) \boldsymbol{J}_{g p}(\boldsymbol{\theta}) \dot{\boldsymbol{\theta}} \\
& +{ }^{\circ b j} \boldsymbol{R}_{G}{ }^{A} \boldsymbol{R}_{G}{ }^{T}(\theta){ }^{0} \boldsymbol{R}_{A}{ }^{T 0} \boldsymbol{R}_{B} J_{f r}(q) \dot{q}
\end{aligned}
$$

ここではべクトル積のための行列演算子 $\hat{\boldsymbol{A}}=[\times \boldsymbol{a}](\boldsymbol{a}=$ $\left.\left[a_{1}, a_{2}, a_{3}\right]^{T}\right)$ を

$$
\hat{\boldsymbol{A}}=[\times \boldsymbol{a}]=\left[\begin{array}{rrr}
0 & a_{3} & -a_{2} \\
-a_{3} & 0 & a_{1} \\
a_{2} & -a_{1} & 0
\end{array}\right]
$$

とし,この表記法を用いて

$$
\begin{aligned}
{ }^{A} \hat{\boldsymbol{R}}_{B A}(\boldsymbol{\theta}) & =\left[\times{ }^{A} \boldsymbol{r}_{B A}\right], \\
{ }^{A} \boldsymbol{r}_{B A}={ }^{A} \boldsymbol{R}_{G}{ }^{T}(\boldsymbol{\theta}){ }^{0} \boldsymbol{R}_{A}{ }^{T}\left({ }^{0} \boldsymbol{r}_{B}-{ }^{0} \boldsymbol{r}_{A}\right) & \begin{aligned}
{ }^{A} \hat{\boldsymbol{R}}_{T}(\boldsymbol{\theta}, \boldsymbol{q}) & =\left[{ }^{A}{ }^{A} \boldsymbol{r}_{T}\right],{ }^{A} \boldsymbol{r}_{T} \\
& ={ }^{A} \boldsymbol{R}_{G}{ }^{T}(\boldsymbol{\theta}){ }^{0} \boldsymbol{R}_{A}{ }^{T}{ }^{0} \boldsymbol{R}_{B} \boldsymbol{f}_{r}(\boldsymbol{q}) \\
{ }^{A} \hat{\boldsymbol{R}}_{G}(\boldsymbol{\theta}) & =\left[\times{ }^{A} \boldsymbol{r}_{G}\right],{ }^{A} \boldsymbol{r}_{G}={ }^{A} \boldsymbol{R}_{G}{ }^{T}(\boldsymbol{\theta}) \boldsymbol{g}_{r}(\boldsymbol{\theta})
\end{aligned}
\end{aligned}
$$

とおいた。 つぎに $\Sigma_{0}$ でみた $\Sigma_{T}$ の角速度べクトル ${ }^{0} \omega_{T}$ は

$$
\begin{aligned}
{ }^{0} \boldsymbol{\omega}_{T}= & { }^{0} \boldsymbol{\omega}_{A}+{ }^{0} \boldsymbol{R}_{A}{ }^{A} \boldsymbol{\omega}_{G}+{ }^{0} \boldsymbol{R}_{A}{ }^{A} \boldsymbol{R}_{G}(\boldsymbol{\theta})^{G} \boldsymbol{\omega}_{o b j} \\
& +{ }^{0} \boldsymbol{R}_{A}{ }^{A} \boldsymbol{R}_{G}(\boldsymbol{\theta})^{G} \boldsymbol{R}_{o b j}{ }^{0 b j} \boldsymbol{\omega}_{T} \\
= & { }^{0} \boldsymbol{\omega}_{B}+{ }^{0} \boldsymbol{R}_{B}{ }^{B} \boldsymbol{\omega}_{T}
\end{aligned}
$$

ただし， ${ }^{G} \boldsymbol{\omega}_{o b j}$ は $\sum_{G}$ でみた $\sum_{o b j}$ の角速度べクトル である. ${ }^{G} \boldsymbol{\omega}_{o b j}=0,{ }^{0} \boldsymbol{\omega}_{A}=0,{ }^{0} \boldsymbol{\omega}_{B}=0$ と (9), (10) 式 を用いて (13) 式を変形して ${ }^{o b j} \omega_{T}$ を求めると

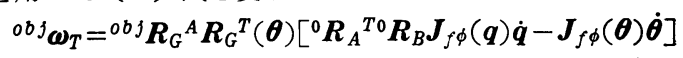

となる（8）式と（14）式をまとめると,

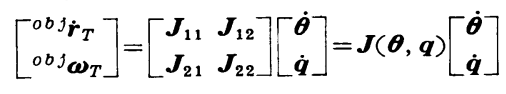


ここで

$$
\begin{aligned}
& \boldsymbol{J}_{11}=-{ }^{\circ b j} \boldsymbol{R}_{G}\left[{ }^{A} \boldsymbol{R}_{G}{ }^{T}(\boldsymbol{\theta}) \boldsymbol{J}_{g r}(\boldsymbol{\theta})\right. \\
& +{ }^{A} \hat{\boldsymbol{R}}_{B A}(\boldsymbol{\theta}){ }^{A} \boldsymbol{R}_{G}{ }^{T}(\boldsymbol{\theta}) \boldsymbol{J}_{g \phi}(\boldsymbol{\theta}) \\
& +{ }^{A} \hat{\boldsymbol{R}}_{T}(\boldsymbol{\theta}, \boldsymbol{q})^{A} \boldsymbol{R}_{G}{ }^{T}(\boldsymbol{\theta}) \boldsymbol{J}_{g \phi}(\boldsymbol{\theta}) \\
& \left.-{ }^{A} \hat{\boldsymbol{R}}_{G}(\boldsymbol{\theta})^{A} \boldsymbol{R}_{G}{ }^{T}(\boldsymbol{\theta}) \boldsymbol{J}_{g \phi}(\boldsymbol{\theta})\right] \\
& \boldsymbol{J}_{12}={ }^{00 j} \boldsymbol{R}_{G}{ }^{A} \boldsymbol{R}_{G}{ }^{T}(\boldsymbol{\theta})^{0} \boldsymbol{R}_{A}{ }^{T 0} \boldsymbol{R}_{B} \boldsymbol{J}_{f r}(\boldsymbol{q}) \\
& J_{21}=-{ }^{o b j} R_{G}{ }^{A} R_{G} T(\theta) J_{g \phi}(\theta) \\
& \boldsymbol{J}_{22}={ }^{o b j} \boldsymbol{R}_{G}{ }^{A} \boldsymbol{R}_{G}{ }^{T}(\boldsymbol{\theta}){ }^{0} \boldsymbol{R}_{A}{ }^{T 0} \boldsymbol{R}_{B} \boldsymbol{J}_{f \phi}(\boldsymbol{q})
\end{aligned}
$$

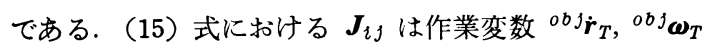
と関節変数 $\dot{\boldsymbol{\theta}}, \dot{\boldsymbol{q}}$ の関俰を表すヤコビアンとなっている.

\section{3 物体の位置が指定される場合の運動学}

ここでは作業対象物の位置は与えられており, 姿勢の 自由度の及存在する場合の協調作業における運動学を検 討する. このような例は, 適当な位固汤体を固定して 作業する場合や，2 章で考えたように物体を与えられた 経路で移動させながら作業をおこなう場合が考えられる。

作業対象物の位置は ${ }^{0} r_{o b j}$ として与えられるとする. これは

$$
{ }^{0} \boldsymbol{r}_{o b j}={ }^{0} \boldsymbol{r}_{A}+{ }^{0} \boldsymbol{R}_{A}{ }^{A} \boldsymbol{r}_{G}(\boldsymbol{\theta})+{ }^{0} \boldsymbol{R}_{A}{ }^{A} \boldsymbol{R}_{G}(\boldsymbol{\theta})^{G} \boldsymbol{r}_{o b j}
$$

と表すことができ，両辺を微分して（6)，（7）式を用 いると,

$$
{ }^{0} \dot{\boldsymbol{r}}_{o b j}={ }^{0} \boldsymbol{R}_{A}\left[\boldsymbol{J}_{g r}(\boldsymbol{\theta})+{ }^{0} \boldsymbol{R}_{A}{ }^{0} \hat{\boldsymbol{R}}_{o b j}(\boldsymbol{\theta}) \boldsymbol{J}_{g \phi}(\boldsymbol{\theta})\right] \boldsymbol{\theta}
$$

たたし、

$$
{ }^{0} \hat{\boldsymbol{R}}_{o b j}(\boldsymbol{\theta})=\left[{ }^{A} \boldsymbol{r}_{o b j}\right],{ }^{A} \boldsymbol{r}_{o b j}=-{ }^{A} \boldsymbol{R}_{G}(\boldsymbol{\theta}){ }^{o b j} \boldsymbol{R}_{G}{ }^{T o b j} \boldsymbol{r}_{G}
$$

(15) 式と（21）式から

$$
\begin{aligned}
& {\left[\begin{array}{l}
{ }^{0 \dot{\boldsymbol{r}}_{o b j}} \\
{ }^{\circ b j} \dot{\boldsymbol{r}}_{T} \\
{ }^{o b j} \boldsymbol{\omega}_{T}
\end{array}\right]=\left[\begin{array}{ll}
\tilde{\boldsymbol{J}}_{o b j} & 0 \\
\boldsymbol{J}_{11} & \boldsymbol{J}_{\mathbf{1 2}} \\
\boldsymbol{J}_{21} & \boldsymbol{J}_{\mathbf{2}}
\end{array}\right]\left[\begin{array}{l}
\dot{\boldsymbol{\theta}} \\
\dot{\boldsymbol{q}}
\end{array}\right]=\boldsymbol{J}_{o b j}(\boldsymbol{\theta}, \boldsymbol{q})\left[\begin{array}{l}
\dot{\boldsymbol{\theta}} \\
\dot{\boldsymbol{q}}
\end{array}\right]} \\
& \text { となる注 2). ここで, } \\
& \boldsymbol{J}_{o b j}={ }^{0} \boldsymbol{R}_{A}\left[\boldsymbol{J}_{g r}(\boldsymbol{\theta})+{ }^{0} \boldsymbol{R}_{A}{ }^{0} \hat{\boldsymbol{R}}_{o b j}(\boldsymbol{\theta}) \boldsymbol{J}_{g \phi}(\boldsymbol{\theta})\right]
\end{aligned}
$$

である。

\section{2台のロボットによる協調作業計画}

ここでは 3 章で導かれた 2 台のロボットによる協調作 業の運動学関係式から協調作業に望ましい作業経路計画 をおこなう。

\section{1 几長自由度}

物体の位置, 姿勢が任意の場合では, (15)式を $[\dot{\boldsymbol{\theta}}, \dot{\boldsymbol{r}}]^{T}$ で解くと,

$$
\left[\begin{array}{c}
\dot{\boldsymbol{\theta}} \\
\dot{\boldsymbol{q}}
\end{array}\right]=\boldsymbol{J}^{-}(\boldsymbol{\theta}, \boldsymbol{q})\left[\begin{array}{c}
{ }^{o b j} \dot{\boldsymbol{r}}_{T} \\
{ }^{0 b j} \boldsymbol{\omega}_{T}
\end{array}\right]+\left(\boldsymbol{I}-\boldsymbol{J}^{-}(\boldsymbol{\theta}, \boldsymbol{q}) \boldsymbol{J}(\boldsymbol{\theta}, \boldsymbol{q})\right) \boldsymbol{y}
$$

注 2 ）（21）式をサブタスクとして後に示す（25）式の $y$ に拘 束条件として組み込む方法もある18)
と表せる。また物体の姿勢は任意で位置は与えられる場 合では, 同様にして（23）式より,

$$
\begin{aligned}
& {\left[\begin{array}{c}
\dot{\boldsymbol{\theta}} \\
\dot{\boldsymbol{q}}
\end{array}\right]=\boldsymbol{J}^{-}{ }_{o b j}(\boldsymbol{\theta}, \boldsymbol{q})\left[\begin{array}{l}
{ }^{0 \dot{\boldsymbol{r}}_{o b j}} \\
{ }^{o b j_{\dot{\boldsymbol{r}}_{T}}} \\
{ }^{o b j_{\boldsymbol{\omega}_{T}}}
\end{array}\right]} \\
& +\left(\boldsymbol{I}-\boldsymbol{J}^{-}{ }_{o b j}(\boldsymbol{\theta}, \boldsymbol{q}) \boldsymbol{J}_{o b j}(\boldsymbol{\theta}, \boldsymbol{q})\right) \boldsymbol{y}_{o b j}
\end{aligned}
$$

と表せる.ここで $\boldsymbol{J}^{-}(\boldsymbol{\theta}, \boldsymbol{q}), \boldsymbol{J}_{o b j}(\boldsymbol{\theta}, \boldsymbol{q})$ はそれぞれ $\boldsymbol{J}(\boldsymbol{\theta}, \boldsymbol{q}), \boldsymbol{J}_{o b j}(\boldsymbol{\theta}, \boldsymbol{q})$ の一般逆行列を表し, $\boldsymbol{y} \in \mathfrak{R}^{12}, \boldsymbol{y}_{o b j}$ $\in \Re^{12}$ はともに任意ベクトルである.

（25），(26）式からも明らかなように2 台のロボット により Fig. 2 で示したような協調作業をおこなわせる ときは，各ロボットは圥長自由度を持たないロボットで あるにもかかわらず，作業を遂行する自由度をのぞいて も自由度が残ることがわかる。

\section{2 几長自由度を利用しない作業計画}

作業が ${ }^{0 b \dot{\boldsymbol{r}}_{T}},{ }^{O b j} \boldsymbol{\omega}_{T}$ で与兄られ，作業対象物の作業 中の位置, 姿勢が任意の場合の関節経路 $[\boldsymbol{\theta}, \boldsymbol{q}]^{T}$ を求め る一つの方法として（25）式の $\boldsymbol{J}^{-}(\boldsymbol{\theta}, \boldsymbol{q})$ に擬似逆行列 $\boldsymbol{J}^{+}(\boldsymbol{\theta}, \boldsymbol{q})$ を用い， $\boldsymbol{y}=0$ とする方法が考光られる.この とき,

$$
\left[\begin{array}{c}
\dot{\boldsymbol{\theta}} \\
\dot{\boldsymbol{q}}
\end{array}\right]=\boldsymbol{J}^{+}(\boldsymbol{\theta}, \boldsymbol{q})\left[\begin{array}{c}
{ }^{\circ b j} \dot{\boldsymbol{r}}_{T} \\
{ }^{\circ{ }^{\circ} \boldsymbol{\omega}_{T}}
\end{array}\right]
$$

ただし

$$
\boldsymbol{J}^{+}(\boldsymbol{\theta}, \boldsymbol{q})=\boldsymbol{J}^{T}(\boldsymbol{\theta}, \boldsymbol{q})\left(\boldsymbol{J}(\boldsymbol{\theta}, \boldsymbol{q}) \boldsymbol{J}^{T}(\boldsymbol{\theta}, \boldsymbol{q})\right)^{-1}
$$

と表せる。これは与えられた作業を遂行しながら各関節 角の変化が少なくなるよらな解を与兄るはずである。 こ のときの与えられた作業を遂行するための各関節の動作 を求めるためのアルゴリズム (Algorithm-A) は次のよ らになる。

\section{Algorithm-A}

Step-1：作業対象物に適当な初期位置・姿勢を与え, 各ロボットの初期関節角度 $\boldsymbol{\theta}_{0}, \boldsymbol{q}_{0}$ を求める. $i=0$ とす る.

Step-2：(27）式を

$$
\left[\begin{array}{c}
\Delta \boldsymbol{\theta} \\
\Delta \boldsymbol{q}
\end{array}\right]=\boldsymbol{J}^{+}(\boldsymbol{\theta}, \boldsymbol{q})\left[\begin{array}{l}
\Delta^{0 b j} \boldsymbol{r}_{T} \\
\Delta^{o b j} \boldsymbol{\phi}_{T}
\end{array}\right]
$$

として, 作業変数 $\Delta^{o b j} \boldsymbol{r}_{T}, \Delta^{o b j} \boldsymbol{\phi}_{T}\left({ }^{o b j} \phi_{T}={ }^{o b j} \boldsymbol{\omega}_{T}\right)$ を(29) 式に代入し， $\Delta \boldsymbol{\theta}, \Delta \boldsymbol{q}$ を求める. $\Delta^{0 b j} \boldsymbol{r}_{T}, \Delta^{0 b j} \boldsymbol{\phi}_{T}$ は与え られた作業変数 ${ }^{0 b j} \dot{\boldsymbol{r}}_{T},{ }^{0 b j} \boldsymbol{\omega}_{T}$ と適当な離散時間間隔 $\Delta T$ により求めることができる. ただし，作業姿勢が ${ }^{0 b j} \boldsymbol{\omega}_{T}$ でなく物理的な意味が明確な, 例えばオイラー角によっ て与えられるときは付録に示す方法により $\Delta^{0 b j} \dot{\phi}_{T}$ に変 換すればよい。

Step-3 : $i+1$ 番目の作業での関節角を次のように求 め, $i=i+1$ として Step-2 にもどり，これらの手順を 繰り返す. 


$$
\left\{\begin{array}{l}
\boldsymbol{\theta}_{i+1}=\boldsymbol{\theta}_{\imath}+\Delta \boldsymbol{\theta} \\
\boldsymbol{q}_{i+1}=\boldsymbol{q}_{\imath}+\Delta \boldsymbol{q}
\end{array}\right.
$$

作業対象物の作業中の位置が指定される場合も同様に して求められる.

\section{3 几長自由度を利用する作業計画}

次に（25）式の任意へクトルy，または（26）式の

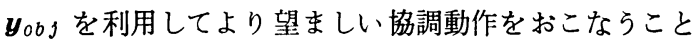
を考える. そこで関節角で表された望ましい動作をおこ ならための評価関数 $V$ 、を

$$
V=V(\boldsymbol{\xi}), \quad \boldsymbol{\xi}=\left[\begin{array}{l}
\boldsymbol{\theta} \\
\boldsymbol{q}
\end{array}\right]
$$

とすれば任意べクトル $\boldsymbol{y}$

$$
\boldsymbol{y}=k \frac{\partial V(\boldsymbol{\xi})}{\partial \boldsymbol{\xi}}
$$

\section{（ $k$ は適当な正定数）}

とすればよい(19). robot-A と robot-B で別の評価関数 を与えたいときは

$$
\begin{gathered}
\boldsymbol{y}=\left[\begin{array}{l}
k_{A} \frac{\partial V_{A}(\boldsymbol{\theta})}{\partial \boldsymbol{\theta}} \\
k_{B} \frac{\partial V_{B}(\boldsymbol{q})}{\partial \boldsymbol{q}}
\end{array}\right] \\
\left(k_{A}, k_{B}\right. \text { は適当な正定数) }
\end{gathered}
$$

のようになる. 評価関数として具体的には可操作度, 操 作力度 (可操作度の逆数), 動的可操作度, 条件数, 障 害物回避を組み込んだものなど ${ }^{20)}$ が考えられるが，これ は経路計画を行らときに与えられた作業に対する固有の 重要性を考虑して決めることになる.

圥長自由度を利用することによってより望ましい協調 動作を行う関節経路を計画するアルゴリズム（Algorithm-B) は次のようになる.

\section{Algorithm-B}

（Stage-1：作業対象物の作業位置，姿勢の決定）

Step-1：作業対象物に適当な初期位置・姿勢を与え， 初期関節角度 $\theta_{0}, q_{0}$ を求める. $i=0$ とする.

Step-2：(25）式を

$$
\begin{aligned}
{\left[\begin{array}{c}
\Delta \boldsymbol{\theta} \\
\Delta \boldsymbol{q}
\end{array}\right]=} & \boldsymbol{J}^{-}(\boldsymbol{\theta}, \boldsymbol{q})\left[\begin{array}{c}
\Delta^{0 b j} \boldsymbol{r}_{T} \\
\Delta^{o b j} \phi_{T}
\end{array}\right] \\
& +\left(\boldsymbol{I}-\boldsymbol{J}^{-}(\boldsymbol{\theta}, \boldsymbol{q}) \boldsymbol{J}(\boldsymbol{\theta}, \boldsymbol{q})\right) \boldsymbol{y}
\end{aligned}
$$

として、yに（32）式のように評価を考虑したものを代 入する. (34) 式で作業变数の増分を $\Delta^{0 b j} \boldsymbol{r}_{T}=0, \Delta^{o b j} \boldsymbol{\phi}_{T}$ $=0$ として $\Delta \boldsymbol{\theta}, \boldsymbol{\Delta q}$ をもとめる. このとさ与觉られた作 業は遂行されず，評価を考虑した望ましい関節角の増分 が得られる.

Step-3 : Step-2 で得られた $\Delta \theta, \Delta q$ により $\theta_{\imath}, q_{\imath}$ を 次のように暩き換える.

$$
\left\{\begin{array}{l}
\boldsymbol{\theta}_{\imath} \leftarrow \boldsymbol{\theta}_{\imath}+\Delta \boldsymbol{\theta} \\
\boldsymbol{q}_{\imath} \leftarrow \boldsymbol{q}_{\imath}+\Delta \boldsymbol{q}
\end{array}\right.
$$

これを Step-1 から Step-3 をでを評価が十分大きくな るまで繰り返す.

(Stage-2 : 作業の遂行に必要な関節角動作の計画)

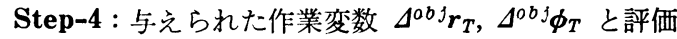
を考虑して決定した $\boldsymbol{y}$ を(34) 式に代入し， $\Delta \boldsymbol{\theta}, \Delta \boldsymbol{q}$ を求 める.

Step-5 : $i+1$ 番目の繰り返し計算における関節角度 を次のようにする.

$$
\left\{\begin{array}{l}
\boldsymbol{\theta}_{i+1}=\boldsymbol{\theta}_{\imath}+\Delta \boldsymbol{\theta} \\
\boldsymbol{q}_{i+1}=\boldsymbol{q}_{\imath}+\Delta \boldsymbol{q}
\end{array}\right.
$$

Step-6 : $i=i+1$ として Step-2 にもどり, これらの 手順を繰り返す.

Algorithm-A との違いは，作業の遂行動作の各ステ ップごとに評価を考慮して位置と姿勢の最適化をおこな っている点である.

作業対象物の作業中の位置が指定される場合も同様に して求められる.

\section{5. 協調作業計画の例題}

ここでは 4 章で提案された協調作業計画法を 2 台の 3 リンク平面運動ロボットの例題に適用する. Fig. 3 に示 すように左側の robot-A の手先に付けられたグリッパ で棈円形をした物体をしっかりつかみ，右側の robot-B の手先に付けられた工具で加工をおこなう．作業は Fig. 4 に示すように工具を棈円の周上で接線方向に対 して 90 度に保ちながら沿わせることで遂行されるもの

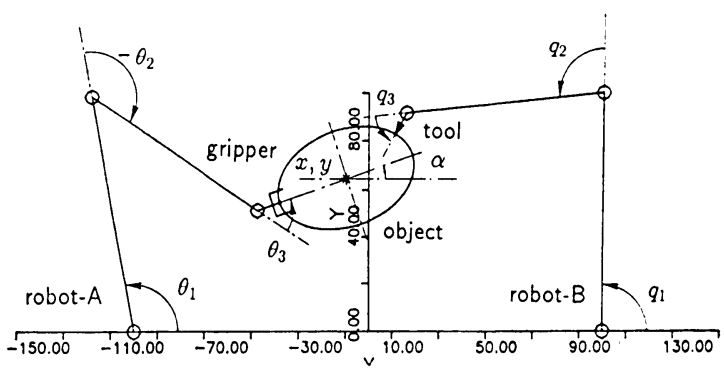

Fig. 3 Numerical example for planning a coordinated work

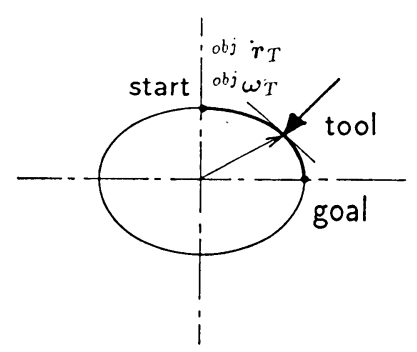

Fig. 4 Specified work 
とする.

各リンクの諸元は, Table 2 に示す. $l_{l}, m_{i}, I_{i}$ はそ れぞれリンクの長さ，質量，慣性モーメントを表わすこ ととし，添え字 $i$ はそれぞれのロボットの第 $i$ リンクを 表わす。

\section{1 作業位置, 姿勢が任意の場合の例題}

Fig. 5, Fig. 6, Fig. 8 は適当な物体の初期位置, 姿 勢 $(x, y, \alpha)=(0.0(\mathrm{~m}), 0.2(\mathrm{~m}), 0.0(\mathrm{deg}))$ から (25)式 あるいは（27）式に従って作業を計画した例である.

Fig. 5 は, 一般逆行列として擬似逆行列を用いAlgorithm-A で得られた経路を示しており，関節角変化が できるだけ少ないようにして作業を遂行している様子が

Table 2 Specifications of robot-A and robot-B

\begin{tabular}{|c|c|c|c|c|}
\cline { 2 - 5 } \multicolumn{1}{c|}{} & $\mathrm{i}$ & $l_{i}(\mathrm{~m})$ & $m_{\mathfrak{i}}(\mathrm{kg})$ & $I_{i}\left(\mathrm{kgm}^{2}\right)$ \\
\hline \multirow{4}{*}{$\mathrm{A}$} & 1 & 1.00 & 10.00 & 3.330 \\
\cline { 2 - 5 } & 2 & 0.85 & 8.50 & 2.040 \\
\cline { 2 - 5 } & 3 & 0.70 & 4.00 & 1.300 \\
\hline \multirow{3}{*}{$\mathrm{B}$} & 1 & 1.00 & 2.50 & 0.8333 \\
\cline { 2 - 5 } & 2 & 0.85 & 2.12 & 0.5088 \\
\cline { 2 - 5 } & 3 & 0.10 & 0.25 & 0.0008 \\
\hline
\end{tabular}

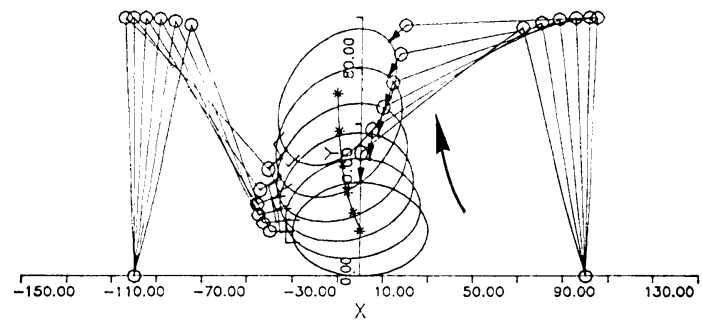

Fig. 5 Coordinated motion to execute the specified work which is obtained by Algorithm-A

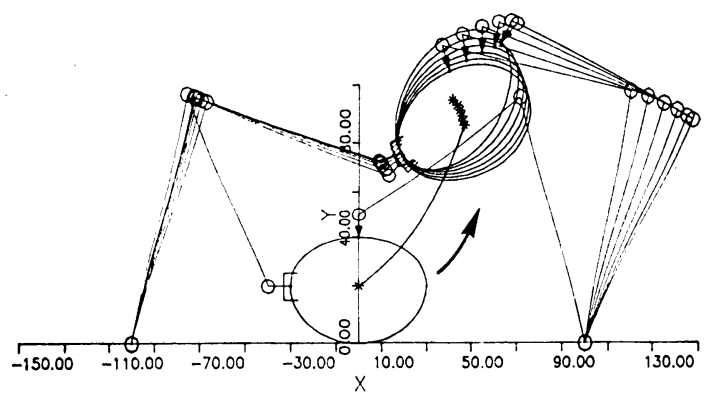

Fig. 6 Optimal coordinated motion to execute the specified work which is obtained by Algorithm-B (Manipulability)
わかる．また，Fig. 6，Fig. 8 は評価にそれぞれ（37） 式（38）式で表される可操作度，動的可操作度を用い Algorithm-B で得られた経路をそれぞれ示している.

$$
\left\{\begin{array}{l}
V_{A}(\boldsymbol{\theta})=\sqrt{\operatorname{det}\left(\boldsymbol{J}_{g r}(\boldsymbol{\theta}) \boldsymbol{J}_{g r}{ }^{T}(\boldsymbol{\theta})\right)} \\
V_{B}(\boldsymbol{q})=\sqrt{\operatorname{det}\left(\boldsymbol{J}_{f r}(\boldsymbol{q}) \boldsymbol{J}_{f r}{ }^{T}(\boldsymbol{q})\right)}
\end{array}\right.
$$

(for Fig. 6)

$\left\{\begin{array}{l}V_{A}(\boldsymbol{\theta})=\sqrt{\operatorname{det}\left(\boldsymbol{J}_{g r}(\boldsymbol{\theta})\left(\boldsymbol{M}_{g r}{ }^{T}(\boldsymbol{\theta}) \boldsymbol{M}_{g r}(\boldsymbol{\theta})\right)^{-1} \boldsymbol{J}_{g r}{ }^{T}(\boldsymbol{\theta})\right)} \\ V_{B}(\boldsymbol{q})=\sqrt{\operatorname{det}\left(\boldsymbol{J}_{f r}(\boldsymbol{q})\left(\boldsymbol{M}_{f r}{ }^{T}(\boldsymbol{q}) \boldsymbol{M}_{f r}(\boldsymbol{q})\right)^{-1} \boldsymbol{J}_{f r}{ }^{T}(\boldsymbol{q})\right)} .\end{array}\right.$

(for Fig. 8)

ここで, $\boldsymbol{M}_{g r}(\boldsymbol{\theta}), \boldsymbol{M}_{f r}(\boldsymbol{q})$ はともに robot-A, robot-B の慣性マトリクスを表している.

Fig. 7, Fig. 9 は，それぞれ Fig. 6, Fig. 8 に対応 する評価値（可操作度, 動的可操作度）を縦軸にとり, 移動経路（step）を横軸にとっている. ただし, 初期位 置, 姿勢から 2 番目のセンターシンボルまでは, Algorithm-B の Stage-1 での初期位置, 姿勢の最適化の様 子を示している. Fig. 6, Fig. 8 とついても 1 番目と 2 番目のセンターシンボルの間は初期位置, 姿勢の最適化 の様子を示しており，この間作業は遂行しない。また比 較のために，擬似逆行列で作業計画をした場合の Fig. 5

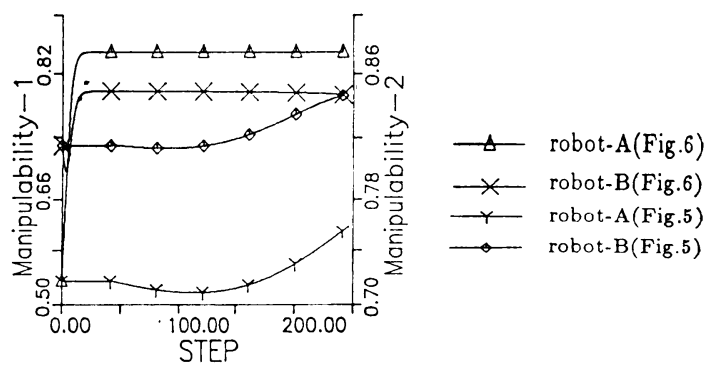

Fig. 7 Index values for the paths of Fig. 5 and Fig. 6

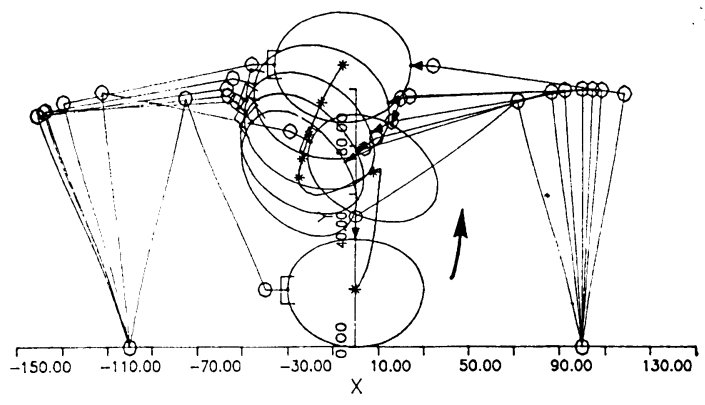

Fig. 8 Optimal coordinated motion to execute the specified work which is obtained by Algorithm-B (Dynamic manipulability) 


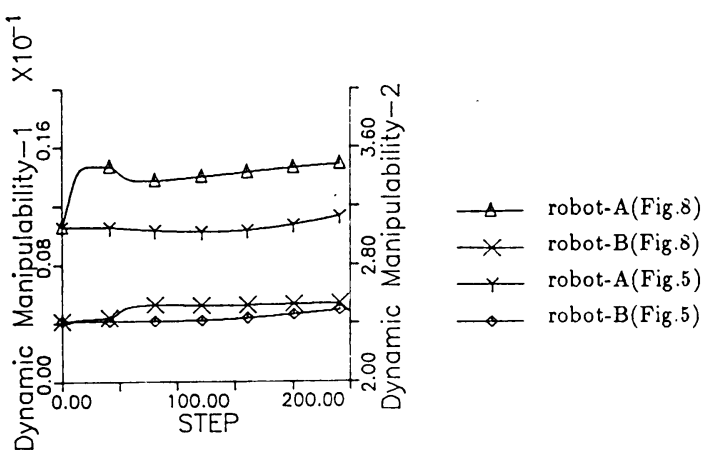

Fig. 9 Index values for the paths of Fig. 5 and Fig. 8

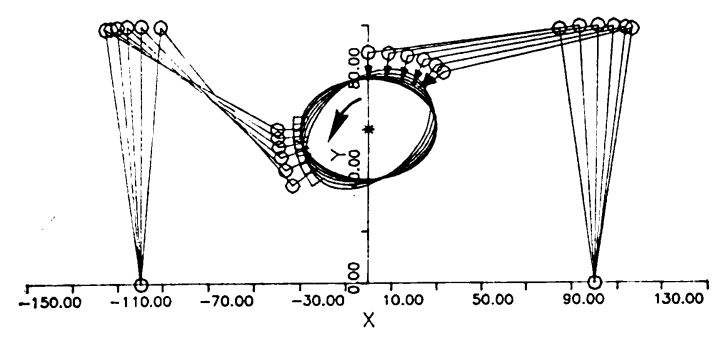

Fig. 10 Coordinated motion to execute the specified work and to stay at the specified point which is obtained by Algorithm-A

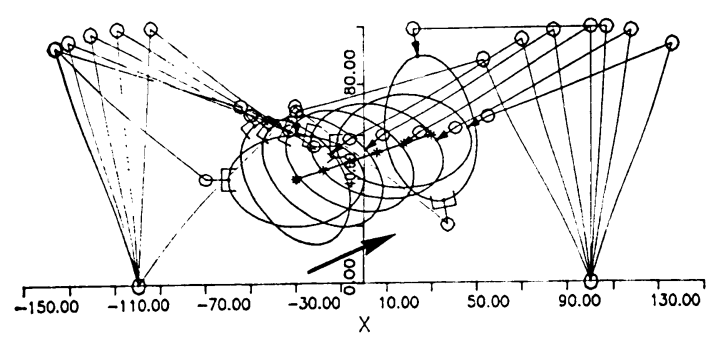

Fig. 11 Coordinated motion to execute the specified work and to follow the specified path of object which is obtained by Algorithm-B (Dynamic manipulability)

に対応する評価値も同時に示している.これらの図から Algorithm-B を用いて咒長自由度を利用した場合の経 路は高い評価を維持しつつ作業が遂行できること, さら にこれは作業開始前の初期姿勢の最適化にかなりの比重

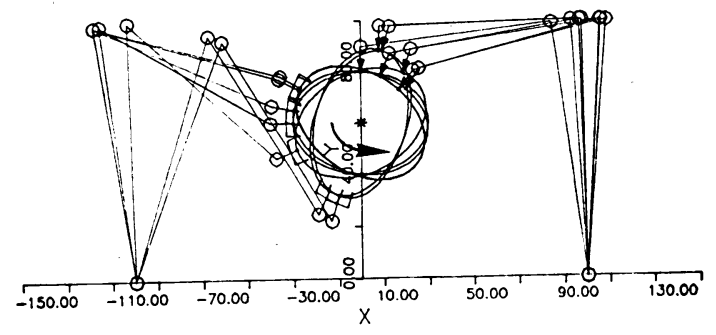

Fig. 12 Coordinated motion to execute the specified work and to stay at the specified point which is obtained by Algorithm-B (Manipulability)

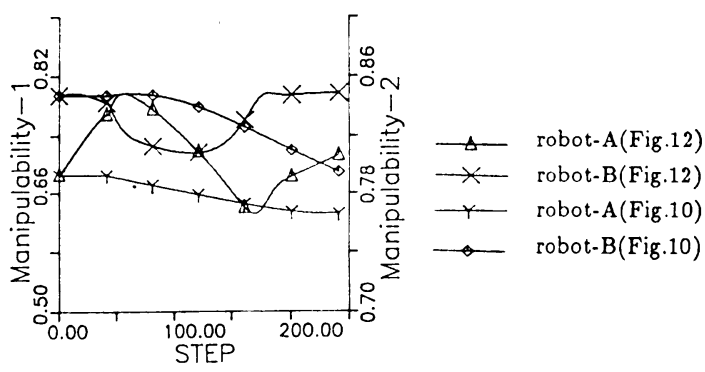

Fig. 13 Index values for the paths of Fig. 10 and Fig. 12

があることもわかる.

\section{2 作業対象物の位置が指定される場合の例題}

Fig. 10, Fig. 12 は物体位置を $\left(x_{o b j}, y_{o b j}\right)=(0.0$ (m), 0.6(m)) に固定して作業をおこなう場合に，ま た，Fig. 11 は直線経路（始端: $(-0.3(\mathrm{~m}), 0.4(\mathrm{~m})) \Rightarrow$ 終端 : $(0.3(\mathrm{~m}), 0.6(\mathrm{~m})))$ にそって物体の重心を移動さ せながら作業を扣こなら場合に対して協調作業関節経路 を計画した例である。

このらち Fig. 10 は，一般逆行列として擬似逆行列を 用いAlgorithm-A により計画した経路を示している. また，Fig. 11，Fig. 12 は評価にそれぞれ動的可操作度， 可操作度を用いAlgorithm-Bにより計画した経路を示 している. Fig. 13 は, Fig. 12 に対応する評価值 (可 操作度) を縦軸にとり，移動経路（step）を横軸にとっ ている、また比較のために，擬似逆行列で作業計画をし た場合の Fig. 10 に対応する評価值も同時に示している. これらの図から作業対象物の位置が指定される場合にお いても，Algorithm-B を用いてて長自由度を利用した 場合の方が作業位置, 姿勢が任意の場合と同様に評価は 全体的に良くなることがわかる。 


\section{6. ま と め}

本研究では，与えられた作業を実現するための複数台 ロボットによる協調的な作業形態を検討し, 協調作業の ための経路計画アルゴリズムを提案した，以下，得られ た結果を示す.

1）協調作業を行う2台のロボットの両手先位置, 姿 勢の運動学的な拘束条件による分類から, 従来あまり検 討されていない作業形態を指摘した.

2） 2 台のロボットを用いた興味深い協調作業形態の 例として，片方のロボットでワークを把持し，もら一方 のロボットで与えられた作業を行ら協調動作を検討し, この作業に対する運動学の定式化を行った.

3）協調作業の運動学式に基づき, 協調動作特有の圥 長自由度を利用した経路計画アルゴリズムを提案した. また 2 台の 3 リンクロボットの協調作業経路計画問題に 提案した方法を適用し，アルゴリズムの有効性を確認し た.

なお, 本研究で提案している経路計画アルゴリズムは 基本的には各時点における瞬時最適化となっており, 得 られた関節軌道が動力学的になめらかになる保証はない。 今後の課題として動力学を十分考虑した協調動作軌道計 画問題が残されている.

\section{付録 作業変数がオイラー角で与えられる場合}

作業変数がオイラー角 $\varphi^{T}=[\alpha, \beta, \gamma]$ の増分 $\Delta \varphi$ で 与えられる場合は

$$
\operatorname{\Delta obj}^{0 b}=\left[\begin{array}{ccc}
0 & -\sin \alpha & \cos \alpha \sin \beta \\
0 & \cos \alpha & \sin \alpha \sin \beta \\
1 & 0 & \cos \beta
\end{array}\right] \Delta \varphi
$$

を用いて $\Delta^{0 b j} \phi_{T}$ に変換すればよい19).

\section{参考文 献}

1）野武 憲, 石見勝弘，真鍋隆夫，“冗長性を利用した口 ボットの協調制御の一手法”, 第 7 回日本ロボット学会 学術講演会予稿集, pp. 659-660, 1989.

2）長尾陽一，太田英明，尾上一彦，中村尚範，“ハンドリ ングアーク溶接ロボットの開発”, 第 8 回日本ロボット 学会学術講演会予稿集, pp. 313-316, 1990.

3）中村仁彦, 永井 清, 吉川恒夫, “複数のロボット機構 による協調的あやつり力学”, 日本ロボット学会誌, Vol 4, No.5, pp. 489-498, 1986.

4) F. Cheng and D.E. Orin, "Efficient Algorithm for Optimal Force Distribution-The Compact-Dual LP Method", IEEE Trans. RA, Vol6-2, pp. 178-187, 1990.

5) C. R. Carignan and D. L. Akin, “Optimal Force
Distribution for Payload Positioning Using a Planar Dual-Arm Robot", ASME J. Dyn. Syst., Meas., and Contr., Vol.111, pp. 205-210, 1989.

6）限下恭介，杉江俊治，小野敏郎，“ 2 次元平面内に打 る 2 本のマニピュレータの協調的操り一定式化と制御形 の設計一”, 日本ロボット学会誌, Vol.7, No.2, pp. 145-153, 1989.

7）内山 勝, ピエール・ドジェ, “両手ロボットの対称型 運動学と非マスタースレーブ協調制御”, 日本ロボット 学会誌, Vol 7, No.1, pp. 19-30, 1989.

8) A. M. Dudar and A. H. Eltimsahy, “A Near-Minimum Time Controller for Two Coordinating Robots Grasping an Object", Proc. of 1990 IEEE Int. Conf. on Robotics and Automation, pp. 1184-1189, 1990.

9) S. B. Moon and S. Ahmad, "Time Scaling of Trajectories for Cooperative Multi-Robot Systems", Proc. of the 29th Conf. on Decision and Control, pp. 1120-1127, 1990.

10) J.E. Bobrow, J. M. McCarthy V. K. Chu, “MinimumTime Trajectories for Two robots Holding the Same Workpiece", Proc. of the 29th Conf. on Decision and Control, pp. 3102-3107, 1990.

11) P. Dauchez and R.Zapata, "Co-ordinated Control of Two Cooperative Manipulators: The Use of a Kinematic Model", 15th ISIR pp.641-648, 1985.

12) V. Kumar and J.F. Gardner, "Kinematics of Redundantly Acutuated Closed Chains", IEEE Trans. RA, Vol. 6-2, pp. 269-274, 1990.

13) S. Lee, "Dual Redundant Arm configuration Optimization with Task-Oriented Dual Arm Manipulability", IEEE Trans. RA, Vol.5-1, pp.78-97, 1989.

14) P. Chiacchio, S. Chiaverini, L. Sciavicco and B. Siciliano, "Global Task Space Manipulability Ellipsoids for Multiple-Arm Systems", IEEE Trans. RA, Vol.7-5, pp. 678-685, 1991.

15) M. K. Jouaneh, Z. Wang and D. A. Dornfeld, "Trajectory Planning for Coordinated Motion of a Robot and Positioning Table : Part 1-Path Specification-", IEEE Trans. RA, Vol6-6, pp. 735-745, 1990.

16) M. K. Jouaneh, D. A. Dornfeld and M. Tomizuka, “Trajectory Planning for Coordinated Motion of a Robot and Positioning Table : Part 2-Optimal Trajectory Specification-", IEEE Trans. RA, Vol.6-6, pp. 746-759, 1990.

17) W. F. Carriker, P. K. Khosla and B. H. Krogh, "Path Planning for Mobile Manipulators for Multiple Task Execution", IEEE Trans. RA, Vol.7-3, pp. 403-408, 1991.

18) Y. Nakamura, H. Hanafusa and T. Yoshikawa, "TaskPriority Based Redundancy Control of Robot Manipulators", The Int. J. of Robotics Research, Vol. 6-2, pp. 3-15, 1987.

19）吉川恒夫，“ロボット制御基礎論”，コロナ社，pp. 109131, 1988.

20) C. A. Klein and B.E. Blaho, "Dexterity Measures for the Design and Control of Kinematically Redundant Manipulators", The Int. J. of Robotics Research, Vol.6-2, pp. 72-83, 1987. 


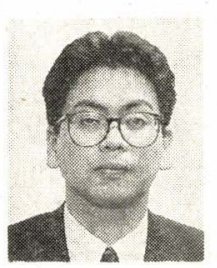

研究に従事. 工学博上.

山本元司

(Motoji YAMAMOTO) 1962 年 7 月 10 日生. 1985 年九州大学 工学部動力機械工学科卒業. 1990 年同大 学院工学研究科博士課程修了 (生産機械工 学専攻), 同年, 九州大学工学部講師. 1992 年同助教授, 現在に至る、ロボット工学の

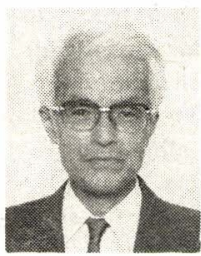

に従事. 工学博士

\section{毛利 彰 (Akira MOHRI)}

1941 年 6 月 23 日生. 1964 年九州大学 工学部生産機械工学科卒業. 1969 年同大 学院工学研究科博士課程単位取得退学 (生 産機械工学専攻). 同年, 九州大学工学部 講師・助教授を経て, 1982 年同教授, 現 在に至る. ロボット工学, 制御工学の研究 (日本ロボット学会正会員)

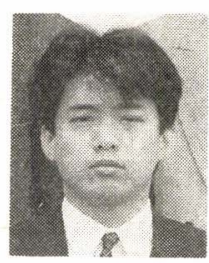

黒田創明 (Soumei KURODA) 1967 年 10 月 23 日生. 1992 年九州大 学大学院工学研究科修士課程修了. 同年, (株)京セラ入社. 